\title{
ALGUMAS QUESTÕES (MUITO PESSOAIS) SOBRE A CRÍTICA LITERÁRIA HOJE
}

\section{Patrícia Trindade Nakagome}

RESUMO: Proposição de algumas questões sobre a forma, o espaço e o sentido da crítica literária brasileira na contemporaneidade. As questões são formuladas a partir de experiências pessoais, mas se espera que elas dialoguem com as dúvidas e angústias de outros pesquisadores da área.

PALAVRAS-CHAVE: Crítica literária; Função da crítica; Dúvidas.

ABSTRACT: It is proposed a few questions about the form, the space and the meaning of Brazilian literary criticism in contemporaneity. The questions are formulated from personal experiences, but it is expected to open a dialogue to other researchers who carry similar doubts and anguish.

KEYWORDS: Literary Criticism; Function of criticism, Doubts. 
Revista Teresa. Qualis A1 (Qualis B4 agora?). Dossiê crítica literária no Brasil. Ótimo. O meu doutorado dialoga com o tema. Para dar conta do prazo de 24 de fevereiro, basta eu recortar o item 2.1.2 da tese, acrescentar uma introdução e conclusão para dar um caráter de texto autônomo. É importante publicar.É importante divulgar a tese. Tenho que fazer isso, ainda que ela esteja disponível on-line e gratuitamente na base da USP, contando até agora com 136 downloads. Eu deveria ter escolhido um título que fosse mais acessível por mecanismos de buscas, pois nem eu mesma consigo encontrar meu trabalho pelo Google. Bem que me sugeriram escolher um título com palavras-chaves. Mas a tese pedia aquele nome, com a marcação do duplo, com a referência a um autor questionado pela crítica: $A$ vida e a vida do leitor. Por que raios eu fui colocar esse título? Que título coloco neste artigo?

1. Na página da própria Revista Teresa, lá no canto direito, há a indicação dos artigos mais visitados. "Aí vem o Febrônio", desde finais de 2014, foi acessado 970 vezes. Penso que o próprio ranking ajuda o artigo, pois eu mesma cliquei nele por me interessar pelo título. $\mathrm{O}$ título de novo, aquilo que tão brevemente rompe a superfície nessa imensidão de tantas letras. Mesmo assim, mesmo com a propaganda involuntária do ranking, foram 970 cliques. Buscando o mesmo "Aí vem o Febrônio" em outra plataforma, noto que ele não foi citado por ninguém (nem pelo próprio autor, o que é tão comum). Isso não quer dizer, é claro, que não tenha sido lido, apreciado por outras pessoas. Ao mesmo tempo, não quer dizer também que tenha sido lido, apreciado por outras pessoas. Bom, é isso o que faz todo o texto, sendo ele sempre potência. Entendo isso, mas não deixo de me perguntar: por que, no meu caso, escrever um artigo que nem terá um bom título como aposta para ser lido?

2. A crítica literária saiu dos jornais e se consolidou como crítica universitária. Com isso, pode-se dizer que o debate que se abria para a sociedade tornou-se cada vez mais restrito, como matéria de especialistas. A diminuição do espaço na grande imprensa não é, como lembra Jobim, ${ }^{1}$ fenômeno exclusivo sofrido pela crítica literária, revelando antes uma mudança na própria mídia impressa. Ela hoje disputa espaço, por exemplo, com a internet, na qual participam poucos críticos, mas em que muitos jovens booktubers partilham suas leituras. A crítica, reduzida na mídia

1 јовім, José Luis. “Crítica literária: questões e perspectivas”. Itinerários, Araraquara, n. 35, p. 153, jul.-dez. 2012. 
impressa e enfocada na universidade, se vê coagida a mais e mais publicações, valorizando aquilo que nem sempre corresponde à tradição da área. Como observa Ginzburg $^{2}$ em interessante estudo, há uma assimetria entre produção e leitura crítica, pois se exige que pesquisadores publiquem em periódicos bem avaliados, mas estes não são objetos frequentes de leitura e citação pelos próprios pesquisadores. Assim, a crítica parece atender a interesses específicos da esfera acadêmica, mesmo que isso nem mesmo faça sentido para a produção de conhecimento da própria área. Se não damos conta de uma produção que atenda aos interesses da área, como pensar em textos que extrapolem o limite dos muros das universidades? A crítica deveria voltar suas preocupações para a própria universidade como forma de fazer jus à sua natureza intrinsecamente acadêmica?

3. Diante de interlocutores imaginários (ou mesmo lembrando de alguns interlocutores reais), prevejo reações à pergunta acima: não, claro que não! Ao pensamos numa oposição persistente na crítica brasileira, entre os chamados culturalistas e tradicionalistas, ${ }^{3}$ podemos reconhecer que ambos, no limite, discutem aquilo que cabe ser deixado como legado literário à sociedade, questionando ou defendendo o cânone. Nos dois polos, temos demonstrações diferentes da relação profunda entre a crítica e a sociedade, revelando uma expansão para além dos muros da universidade. Seria, desse modo, negativa a resposta para a pergunta anterior. Poderíamos pensar então que sim: a crítica é (ou pode ser muitas vezes) preocupada com a sociedade e trata

2 Ginzburg, Jaime. "Periódicos acadêmicos: antagonismo entre produção e leitura (notas sobre revistas da área de Letras publicadas em 2013)”. Revista Expedições: Teoria da História \& Historiografia, vol. 5, n. 1, jan.-jul. 2014.

3 Mello, ao rastrear o debate crítico por meio de documentos da Abralic, termina seu artigo apontando para dois polos que se consolidavam no debate crítico: "Porque, ao que tudo indica, começa a se firmar, a partir dos anos 2000, um cenário com dois fenômenos simultâneos, em oposição: de um lado, haveria o crescimento, a ampliação e a segmentação das formas da literatura e da cultura contemporâneas, com a chegada de novos agentes à cena literária; e, de outro, a restrição de métodos, de linguagem e de objeto, em uma lógica que poderíamos chamar de especialista, vinda tanto de criadores quanto de críticos literários consagrados, com o objetivo de conter a invasão bárbara e os 'democratismos' propiciados não apenas pelos estudos culturais mas principalmente pelas novas mídias e pela indústria cultural, que tendem a desregulamentar o mercado editorial e as especificidades do campo literário". MELLo, Jefferson Agostini. “Uma associação itinerante”. Estudos de Literatura Brasileira Contemporânea, n. 44, pp. 37-63, jul.-dez. 2014, p. 61. 
dela, mas, ainda assim, é voltada para os pares, que estão dentro da universidade. Eles são os seres concretos (com nomes e titulações) que estão no horizonte de um texto, não a sociedade. Esse fato dialoga, por exemplo, com um episódio ocorrido na Feira de Frankfurt de 2013 em que o Brasil era o país homenageado. Na mesa em que estavam Patrícia Melo e Ferréz, foi feita uma pergunta sobre os leitores de suas obras. A primeira disse que escrevia a um leitor geral, deixando a Ferréz então a pergunta, pois ele lidava mais diretamente com seu público. A partir disso, podemos considerar que há uma diferença sensível em estabelecer um diálogo com leitor/ público e, de fato, aproximar-se deles. Se fazer crítica é, de modo geral, falar para os pares, modificamos então a pergunta do tópico anterior: se a crítica tem sim preocupações que abarcam a sociedade, faz sentido buscar formas de se aproximar dela?

4. Na pergunta anterior, pensei em "formas" de aproximação num sentido amplo. Mas consideremos inicialmente o debate mais específico sobre a forma do texto crítico. Impossível não lembrar de Adorno ${ }^{4}$ em seu célebre texto sobre o ensaio, defendido em oposição ao tratado. Na atualização do debate, concordamos com Durão no sentido de que a oposição hoje seria entre o "ensaio e ele mesmo, ou seja, entre o ensaio de verdade, e o ensaio como invólucro do fast food paper, um produto burocrático e feito às pressas". A oposição é legítima. Eu mesma iniciei este texto revelando meu intuito de recortar uma parte de minha tese para produzir mais um artigo, sempre necessário para a carreira. Quando estava prestando concurso, escrevi muitos textos por saber que eles me dariam pontos fundamentais em provas cheias de tabelas. Nessa escrita movida pela necessidade, há certamente muito a ser questionado. No momento, interessa-me pensar se a melhor alternativa a essa distorção "fast food paper" é, de fato, o ensaio de verdade. (Imagino aqui olhares de desdém a essa afirmação, afinal, ela pode ser motivada por eu não ter condição de escrever um verdadeiro ensaio ou por não entender a seriedade de uma área como a nossa, que exige a reflexão detida, bem articulada e embasada.) O que penso, porém, é que o ensaio de verdade, justamente por ser tão de verdade, se apresenta exatamente como... verdade. Neste semestre, durante uma disciplina, uma aluna falou algo que me pareceu significativo:

4 Adorno, Theodor W. “O ensaio como forma”. In: Notas de literatura I. São Paulo: Editora 34, 2003. 5 DURão, Fábio Akcelrud. "Por uma crítica da multiplicidade nos estudos literários”. Via Atlântica, São Paulo, n. 23, p. 78, 2013. 
"todos os textos são tão bons que, quando eu leio sozinha, concordo com todos eles". Mesmo que tivessem posicionamentos antagônicos, eles geravam sua adesão. E aí, estar em sala de aula era um processo de colocar em questão, de pensar junto. A aula tem o inesperado em sua forma. Há algo do inacabado e do imprevisível que permite o debate e a divergência. É claro que o ensaio de verdade também o possibilita, caso contrário não geraria tantos novos ensaios e comentários. Mas, para responder a algo tão de verdade, por vezes é necessária uma tese, são necessários muitos anos. Claro que são necessários tempo e repertório para construir o conhecimento, de modo que não me posiciono contra método e seriedade, mas contra o que pode ser sufocado no processo de formação, na pergunta que deixa de ser feita com medo de ser tola diante de um ensaio de verdade. Assim, ainda que também duvide da importância do "fast food paper", não sei se algumas pontas soltas na escrita são completamente negativas. Por isso talvez posts no Facebook (os posts "de verdade", para mantermos a oposição proposta por Durão) me pareçam tão proveitosos. Há algo de instável ali que permite pensar, que abre com mais facilidade ao diálogo e à reflexão. Será que a forma de escrita acadêmica precisa ser necessariamente a melhor forma?

5. “Que canto há de cantar o indefinível?" temos questionado no poema "De noite" de Hilda Hilst. ${ }^{6}$ Qual a forma que lida com a instabilidade e a dúvida? Não com a dúvida que, no processo de sua formulação, pode chegar a ocultar seu sentido, como poderíamos apontar em relação a Pode o subalterno falar? de Spivak.7 Em alguns momentos, chego a questionar: "Pode o leitor compreender?", pois ainda que este não seja o texto mais complexo da autora, já revela, conforme critica Eagleton, ${ }^{8}$ como a autora lida com o outro imediato, o leitor, ainda que se preocupe com o Outro do Pós-colonialismo. Há motivos diversos para uma escrita hermética, mas eles possivelmente não passam por uma expansão do diálogo com pessoas menos versadas nos textos acadêmicos. Talvez eu esteja, mais uma vez, pedindo à crítica literária algo que não lhe cabe, já que se trata

\footnotetext{
6 HILst, Hilda. Do desejo. São Paulo: Globo, 2004.

7 SPIVAK, Gayatri. Pode o subalterno falar? Belo Horizonte: Editora UFMG, 2010.

8 "Post-colonial theory makes heavy weather of respect for the Other, but this most immediate Other, the reader, is apparently dispensed from this sensitivity. Radical academics, one might have naively imagined, have a certain political responsability to ensure that their ideas win an audience outside senior common rooms." EAGLETON, Terry. Figures of Dissent. London: Verso, 2005, p. 159.
} 
de uma discussão produzida por especialistas. Foi isso que notei desde o início da graduação em Letras, em foi pedido que a turma lesse um texto sobre poesia que, a cada página, obrigava à leitura de citações em espanhol, inglês e francês. Quando eu achava que tinha vencido as barreiras, veio o latim! Após tanto consultar os dicionários, não podia sequer entender o sentido mais geral do texto. Minha possibilidade de pensar com o texto e a partir dele foi minada. Restavam apenas o professor e suas explicações. Eram as respostas dele, dadas às minhas não formuladas questões. Talvez a clareza não seja o imperativo que eu reclame aqui, mas o claro intuito do debate, que, penso eu, não se instaura se o leitor mal é capaz de compreender o texto. E muitos deles, para garantir que sejam aceitos, para comprovar o conhecimento do seu autor, não se abrem a isso. Ao invés de perguntas, oferecem respostas fechadas em frases complicadas ou ideias que se repetem à exaustão, garantindo que nada escape ao controle. Com tanto controle, como pensar o novo? Como duvidar? Diante de textos muito bem feitos, capazes de explorar ao máximo o pequeno recorte que propõem, sinto desânimo. Como confessar o desânimo diante de um texto, ou tantos textos que, com nomes diferentes e mesmo com assuntos diferentes, parecem se repetir?

6. Se o desânimo é meu, provavelmente a falha é minha. Quantas vezes já não pensei: eu não compreendo, eu não me interesso, eu, eu. ${ }^{9} \mathrm{E}$ aí, voltando à observação de que a crítica literária é essencialmente uma atividade universitária, feita para seus pares, o meu desinteresse por alguns textos celebrados apenas indicaria minha condição de pária. Não há, é certo, a necessidade de que eles almejem conquistar minha adesão, apreço ou leitura. Afinal, entendendo o texto como potência, sei que ele pode fazer sentido para alguns leitores e para outros não. Mas é estranha a sensação, diante de leituras realizadas em eventos, de que não sou apenas eu que sinto desânimo. Em congressos, olho para os lados e vejo, no rosto de professores, a indiferença que

9 É um movimento diferente do tédio confessado por Franchetti, que, ao afirmar seu tédio em relação à crítica literária brasileira contemporânea, aponta as falhas dessa crítica, especialmente quanto ao seu receio de emitir juízos negativos: "Por isso, na encenação da cultura, nos lugares onde ela se encena mais, como nos cursos universitários e nos jornais e revistas literárias, tudo se passa como se as pessoas cultas, por isso mesmo de serem cultas e quererem parecer cultas, fossem dispensadas de emitir julgamento negativo em forma definitiva, em forma escrita, sobre os produtos perecíveis do presente. A atitude preferencial quanto ao presente consiste numa constrangida suspensão do julgamento". FRANCHETTI, Paulo. “A crítica morreu?". Jornal da Unicamp. Campinas, 2 a 8 ago. 2004. 
reconheço nos piores momentos de alguns dos meus alunos. Ou seja, em um evento com grandes nomes da área, não é raro que professores manifestem fisicamente (em corpos escorregados em cadeiras ou dedos nos celulares) a mesma atitude que tanto os incomoda em seus alunos. Talvez não seja apenas eu. Por isso talvez haja o incômodo de uma plateia sem perguntas, que exige do mediador formular uma questão que é lançada como colete salva-vidas ao palestrante. Assim, para além de limitações que certamente são minhas, penso que há, em alguns casos, uma falta de preocupação para com o outro, com aquele que se senta diante das palavras ditas e escritas do autor. Há uma preocupação com o rigor do objeto, que obriga a leitura do texto para garantir a precisão, as várias citações para atestar conhecimento, os tantos detalhes para comprovar o ponto a ser defendido. Não parece haver preocupação se aquele que está no auditório sente sono, pois muitas vezes a cabeça do palestrante pouco se distancia do papel lido. Lembro-me da polêmica em torno da participação de Bernardo Carvalho na Flip 2016, em que teria afirmado: "Não me interessa se o leitor lê ou não lê; eu quero que se foda. O que eu quero é fazer minha literatura". ${ }^{10}$ Não me alongo no sentido da afirmação do autor ou nos desdobramentos em torno dela. Apenas recorro a essa citação para questionar se, sem palavrão, não é isso o que ocorre em muitos eventos e na publicação de muitos artigos. Há uma afirmação nem sempre evidente sobre a necessidade e o desejo de apresentar o próprio texto. A responsabilidade é consigo mesmo, com o objeto, não com o outro. Não se trata, vejamos, de uma falta de habilidade em atingir o outro, pois ninguém escreve ou fala com quaisquer garantias. Talvez não haja uma preocupação com o ouvinte/leitor simplesmente porque se imagina que ele se assemelha ao autor, afinal, se há um encontro entre eles, é porque ambos aceitaram partilhar a mesma revista ou evento. Se é assim, como eu posso me queixar de um evento ou texto que escolhi? Como confessar o sono diante daqueles que escolhi como meus pares?

7. Se desanimo diante de um texto e tenho sono em apresentações, por que continuo a ler e a escutar? Ou ainda mais: a escrever e a falar? Essa dupla pergunta é recorrente companheira. Eu leio e escuto o outro pela promessa da surpresa. E nos últimos anos, tenho encontrado, aqui e lá, textos que me instigam, que me convidam a pensar e me

10 Carvalho, Bernardo. “Não me interessa o leitor' diz Bernardo Carvalho em mesa na Flip”. Folha de S.Paulo. São Paulo, 17 jul. 2016. 
colocam em questão. Não os encontro com a frequência que gostaria, com a frequência que imagino arrebatar outros colegas, mas encontro. E me movo por essa possibilidade. Quando, porém, assumo a condição ainda mais ativa de escrever e falar, a pergunta é mais incômoda. Olhando para trás, sei que muitas vezes escrevi por necessidade. A tese de doutorado não foi assim, porque ela dava forma à questão que me acompanhava por muito tempo e porque eu sabia que ela seria lida ao menos por minha orientadora e pela banca. Com exceção da tese e de alguns outros poucos artigos, escrevi porque precisava. Estabeleci parcerias com grandes amigas para dividir o ato da escrita não porque quisesse "maximizar" a minha "produção" individual (ah, esse vocabulário que nos revela), mas porque me amparava no desejo delas por escrever para também formular as minhas incertas palavras. Escrever com elas sempre teve um significado especial, porque era uma forma de celebrar a amizade e pensar junto no texto, colocando no papel muito do que antes tinha gosto de café. Já escrever sozinha, cercada por um receio constante de silêncio, ocorre fundamentalmente por conta da necessidade. Eu sabia que, com o fim do doutorado e o início da terrível fase de concursos públicos, eu precisaria ter um lattes "competitivo". Na condição de recém-doutor, enfrentando tabelas que pontuavam cargos de coordenação de pós-graduação ou chefia de departamento, só restava garantir os pontinhos com publicação. E eu fiz isso. Por que continuar escrevendo se agora já não tenho mais essa necessidade?

8. Este é o primeiro artigo que tento escrever depois de me tornar professora. E comecei, como anunciei no início, porque uma vez mais, e talvez por muito tempo, tenho a necessidade de escrever. Para não ter problemas com o estágio probatório, preciso continuar publicando. Se quiser ser credenciada na pós-graduação, preciso de $X$ artigos. E aí, sigo eu com meus textos. E, vejamos bem, não acho que haja problemas em cumprir algo esperado pelas atribuições do meu trabalho. Não apenas na universidade, mas em outros empregos, realizei tarefas que não compreendia bem, mas que me eram exigidas. Escrevo porque esperam isso de mim, portanto. Talvez a questão seja então: como escrever sobre algo que pareça necessário a mim?

9. Parece que de tantas coisas que precisava fazer, eu não pensava mais no porquê de querer estar na posição de alguém que escreve artigos. E aí foi necessário olhar para o passado. Antes de querer ser professora universitária, quando optei pelo curso de Letras, eu queria ser professora. Professora apenas, sem delimitar o nível de atuação. Lembrar isso me faz pensar nesse processo de transformação que me levou 
do desejo de trabalhar com educação para o desejo específico de ser professora universitária. Pelo que sei, isso não aconteceu só comigo. E acho que, entre outros fatores, isso tem relação com o fato já mencionado de que a crítica se mostra como uma atividade essencialmente acadêmica. Se aprendemos, ao longo da graduação, a admirar textos críticos, a nos encantar com o repertório de nossos professores, entendemos que apenas podemos alcançar a mesma realização se tivermos um trabalho específico: professor universitário de instituição pública. Logicamente esse desejo também está relacionado aos benefícios de uma carreira que, apesar das tantas reclamações, ainda fornece o tempo para ler, algo mais limitado na educação básica, com a quantidade insana de aulas e tarefas. As sabidas dificuldades de atuar no ensino fundamental e médio não podem ser negadas, mas, penso eu, há algo mais que afasta futuros professores das escolas e que é, de alguma forma, causado pela própria universidade, pelo fato de compreendermos que a crítica apenas é feita dentro da universidade e para a universidade. Por conta disso, há uma desvalorização de quem leva seu título de mestrado ou doutorado para uma escola. Esse olhar torto para quem atua na educação básica com sua alta titulação nem sempre condiz com o inflamado discurso de apoio aos alunos de ocupações, de valorização da carreira docente etc. Valorizamos, sim. No outro. Talvez isso, somado a tantos outros fatores que não temos como detalhar aqui, explique os concursos com mais de cinquenta candidatos doutores para trabalhar com literatura na universidade. Não parece haver alternativa fora desse espaço. Digo isso lembrando que também não havia para mim, por isso, como mencionei, fiz tudo o que estava ao meu alcance (inclusive o extenso lattes) para disputar uma dessas vagas. Isso ocorreu com uma pessoa que entrou no curso de Letras para ser professora e que saiu de lá achando que isso não era suficiente. Ao olhar em retrospecto, só posso perguntar com Drummond: "Por que motivo as crianças, de modo geral, são poetas e, com o tempo, deixam de sê-lo?"." O que muda (ou se perde) no processo formativo?

10. E por que eu queria ser professora? Porque queria, como o meu professor Francisco diante de uma turma agitada de um curso técnico em Mecânica, mostrar para adolescentes o quanto podia ser incrível ler José de Alencar (Alencar, quem diria!).

11 ANDrade, Carlos Drummond de. “A educação do ser poético". Arte e Educação, ano 3, n. 15, p. 16, out. 1974. 
E eu achava, sem conhecer o famoso "Direito à literatura", ${ }^{12}$ que todas as pessoas mereciam ter acesso a livros como O Guarani (O Guarani, quem diria!). E eu achava, verdadeiramente, que poderíamos viver num lugar melhor se isso fosse possível. Estudar no curso de Letras, por um lado, descortinou um universo com autores mais impressionantes que Alencar; por outro, me levou a questionar o impacto possível da literatura na sociedade. É bom não ter tanta ingenuidade diante do mundo e do papel que posso exercer nele. Mas um pouco mais de fé talvez não fosse ruim. De tempos em tempos, eu retomava esse ímpeto: fui para a Nicarágua e Timor-Leste atrás dessa possibilidade de "fazer a diferença" por meio da língua e da literatura. Tinha que ir tão longe? Não podia ser aqui? Ir para esses lugares, hoje eu penso, rendia algum diferencial. Dar aulas aqui, em alguma das tantas escolas, me colocaria junto à massa de professores. Toda autoria, toda a preocupação em ter/ ser "um nome" é justamente para fugir à massa, não é mesmo? Não é para isso que se escreve também? Mas é para isso que eu escrevo? Como escrever para fazer jus a todas as boas (e ingênuas) intenções que me motivaram lá no passado?

11. Em alguns episódios do meu percurso acadêmico, eu quis falar verdadeiramente. Nem sempre tive êxito. Por isso, um texto como este se move pelo anseio por debate, mas com o receio do silêncio e do silenciamento. Num congresso realizado no exterior, que tinha como uma das linhas "Literary Criticism: Privilege, Luxury, Responsibility?", eu achei que estava diante da oportunidade de discutir com outras pessoas sobre as minhas tantas dúvidas sobre o papel da crítica hoje. O tema parecia propor essa questão, mas o fato é que todos já tinham respostas e estavam muito tranquilos com o papel desempenhado. E não há problema nisso, afinal cada um deve estar ciente de suas motivações e atuação, que não precisa coincidir com as minhas dúvidas. O incômodo é causado pelo "tapinha nas costas" como resposta à inocência da pergunta. Como desdobramento desse evento, conversei com uma professora importante da área, que dizia entender minhas questões e afirmava que eram as dela também. Dava sugestões de como apresentar tais questões, de modo que não fosse tão assertiva (como poderia ser assertiva se fazia perguntas?). Eu poderia, assim, fazer um artigo sobre $X$ ou $Y$, tateando as minhas questões pelas bordas. Bom conselho, como recebi também durante o doutorado, revelando a preocupação verdadeira de quem conhece a uni-

12 CANDido, Antonio. “O direito à literatura”. In: Vários escritos. São Paulo: Duas Cidades, 1995. 
versidade melhor do que eu. O que me intrigava, porém, era: o que a gente perde no processo de tratar nossas questões pelas bordas? Num momento em que tantos temas que envolvem o outro estão no centro do debate, por que pode ser ofensivo falar sobre nós e questionar nosso papel enquanto críticos literários? Qual é o mal em perguntar de frente: o que significa fazer crítica literária hoje num país como o Brasil? Qual é o sentido esperado na atuação do crítico hoje?

12. Volto a Bernardo Carvalho. No mesmo evento em que manifestou sua indiferença em relação ao leitor, afirmou, em resposta a Benjamin Moser, que no nosso país é possível partir do pressuposto de que o leitor é burro: "Claro que pode! O Brasil é um país de analfabeto e um país onde se passa fome: então não escreva livros; plante tomate". ${ }^{13}$ Mais uma vez, não é possível negar o incômodo com o tom da afirmação. Mas, para ser coerente com a minha colocação de que talvez o "ensaio de verdade" não seja a melhor forma para estimular o debate, considero que as colocações de Carvalho cumprem o papel de engendrar questões, como inclusive se viu em redes sociais. Tal como na afirmação em relação ao leitor, o escritor defende o direito de escrever sem pensar numa finalidade, ainda mais ao se considerar a especificidade da formação da população brasileira. Não concordo que a soma de analfabetismo e miséria conduza à burrice, mas creio não ser possível negar que esses fatores trazem impacto para o nosso campo literário. Para lidar com essa adversidade, não basta levar a sério a alternativa irônica de Carvalho, substituindo livros por tomates. Mas há que se considerar que a escrita (literária e crítica) se assenta sobre condições diversas daquelas encontradas em países que muitas vezes nos inspiram em referenciais artísticos e críticos. Se entendemos, com Roberto Schwarz, ${ }^{14}$ que Machado de Assis teria uma obra singular por revelar o desajuste entre uma realidade social de escravidão e a ideia de uma sociedade livre, poderíamos questionar: como escrever considerando a fratura do analfabetismo e da miséria? A crítica literária deve lidar (ou como deve) com o fato de estar na "periferia do capitalismo"?

13. Acredito que a maior parte dos críticos responderiam afirmativamente à questão acima, inclusive dizendo que já age necessariamente considerando as dificuldades

13 CARvalho, Bernardo, op. cit.

14 SCHWARz, Roberto. Um mestre na periferia do capitalismo: Machado de Assis. São Paulo: Editora 34, 1990. 
de se estar num país periférico. Muitas pesquisas e artigos lidam com essa realidade. Os que não o tratam como assunto, resistem às necessidades imediatas de "plantar tomate". Fazer crítica em um país como o Brasil obriga, de alguma forma, a reagir à nossa realidade. A questão, porém, talvez seja assumir que, como indivíduo, me parece que lidar de fato com essa realidade obriga a uma ação. E é difícil assumir tal posição, pois conheço todo o extenso debate sobre a função da literatura, sabendo de toda a desconfiança quanto a um caráter pretensamente "utilitarista". Tendo isso em vista, é difícil clamar por uma intervenção da crítica, que vai além do sentido da escrita que venho tratando ao longo deste artigo. É difícil retomar o meu pensamento antigo de que preciso pensar em formas de intervenção prática, além do texto. Assim, o debate sobre o cânone, por exemplo, com suas tantas discussões sobre obras que devem ou não ser consideradas como literatura, tem, no horizonte, o concreto fato de que tanta gente sequer irá ler, sejam obras ditas de literatura ou não. E no meu caso, me incomoda que tantas pessoas não possam ler e não possam, de alguma maneira, defender a própria posição sobre o cânone ou outros temas mais relevantes. E dizer isso recai em ingenuidade, eu sei. Por que falar sobre isso em um artigo acadêmico, já esgotando o limite dos 30 mil caracteres? Porque eu (muito longe de falar por um nós) sinto a necessidade de pensar em formas de intervenção. E tenho medo / vergonha de mal saber por onde ir. Nesse período sem aulas do meu primeiro ano como finalmente "professora de universidade pública", passei as semanas pensando em ementas esquisitas em que, junto ao título convencional, proporia uma questão para ver se alguém se animaria a respondê-la comigo (algo como: “Tópicos especiais de literatura: como a literatura pode salvar o mundo?”). O que eu encontraria? Quem eu encontraria nessa pergunta? Tracei planos de ir a escolas públicas para desenvolver atividades de leitura, discutindo possibilidades com algumas das amigas com quem antes escrevia artigos. Este texto também é uma forma de ação. Um exercício que me faz encarar minhas dúvidas e ter receio de partilhá-las, revelando minhas fraquezas. Tenho receio de como este texto pode ser lido (se é que seja lido). Mas escrevo porque tenho mais medo ainda de permanecer sempre tão sozinha com as minhas questões. Este texto, no final das contas, só busca perguntar: será que alguém quer pensar comigo formas de intervenção? Para além da forma do texto?

14. Em "Não há inimigo pior do conhecimento que a terra firme", Renato Janine Ribeiro nos pede para lembrar que "nas Humanas, nada é apenas objeto, porque sempre, 
de alguma forma, tem a ver intimamente com o sujeito que o está estudando". ${ }^{15}$ Talvez por isso fujamos à primeira pessoa, tal como Graciliano Ramos ${ }^{16} \mathrm{em}$ sua obra autobiográfica, Memórias do cárcere. Uso aqui a primeira pessoa pela necessidade de reforçar textualmente que não quero, em momento algum, dizer o que outros devem fazer. Pois também não gostei, com as melhores ou piores intenções, quando fui dissuadida de fazer o que queria e de dizer o que me parecia verdade. Posso apenas falar por mim, apresentar as minhas questões. Talvez como síntese de um receio que cerca este texto, transformaria em questão as afirmações de Caio Fernando Abreu em "Itinerário": "Não quero. Não posso restar nu, despojado de mim mesmo. Não posso recomeçar porque tudo soaria falso e inútil. As minhas verdades me bastam, mesmo sendo mentiras. Não é mais tempo de reconstruir". ${ }^{17}$ Não é mais tempo de reconstruir?

15. Como em Grande Sertão: veredas, "quero contar é o que eu não sei se sei, e que pode ser que o senhor saiba". ${ }^{18}$ Quero abrir um espaço para diálogo para além do círculo de amigos, de preocupações que sei serem partilhadas. Fiz isso em outro artigo ${ }^{19} \mathrm{e}$ recebi um retorno, que foi único, apenas um e especial. Quem sabe há mais alguém por aí que tenha questões que sendo, como indico no título, tão pessoais, não sejam exclusivamente minhas? Quem sabe possamos pensar e agir juntos?

Patrícia Trindade Nakagome é Professora Adjunta da Universidade de Brasília

\footnotetext{
15 RIBEIRo, Renato Janine. "Não há inimigo pior do conhecimento que a terra firme”. Tempo Social: Revista de Sociologia da UsP, São Paulo, n. 11, pp. 189-195, maio 1999, p. 193.

16 Ramos, Graciliano. Memórias do cárcere. Rio de Janeiro: Record, [1953] 1989.

17 ABReu, Caio Fernando. "Itinerário". In: Caio Fernando Abreu: O essencial da década de 197o. Rio de Janeiro: Nova Fronteira, 2014.

18 ROSA, João Guimarães. Grande Sertão: veredas. Rio de Janeiro: Nova Fronteira, 2001, p. 227.

19 Cf.: , 2014.
} 